\title{
ARTICLE
}

\section{Study on the Reference Plants for the Assessment of Radiation Impact on Non-Human Species in Southwest of China}

\author{
Jianguo LI*, Baohua HAN, and Binghui MA \\ China Institute for Radiation Protection, Taiyuan, 030006, China
}

\begin{abstract}
This paper introduces the researches on terrestrial reference plants in a area of southwest of China, including selection of candidate reference plants, the description of geometric characteristics, and the transfer factors of ${ }^{90} \mathrm{Sr}$, ${ }^{137} \mathrm{Cs}$, and Pu in plants. The plant species involved are 2 trees (Firmiana simplex, Cryptomeria fourtunei), 2 shrubs (Nerium indicum Mill, Vitex negundo Linn), and 1 herb (Artemisia umbrosa). Expected values of the soil-to-plant transfer factors are provided. Further researches on radiation protection of non-human species in China are discussed.
\end{abstract}

KEYWORDS: non-human species, reference plants, ${ }^{90} \mathrm{Sr},{ }^{137} \mathrm{Cs}, \mathrm{Pu}$, transfer factors

\section{Introduction}

The aim of ionizing radiation protection is not only to protect people and to protect non-human species as well. This change of concept has made the development of a framework for radiation protection of non-human species in urgent need.

The framework including reference organisms, an agreed set of quantities and units, a set of reference dose models, and reference dose-per-unit-intake data are discussed in ICRP Publication $91^{1)}$. The Commission is developing a set of reference fauna and flora, plus their relevant databases - in a manner similar to that of Reference $\mathrm{Man}^{2}$.

The impact assessment of radioactive effluents from nuclear facilities on ecological environment is requested in Chinese environmental codes and regulations, but the framework for assessing the impact of ionizing radiation on non-human species in China is not yet established.

The researches of reference plants are conducted in an area in southwest of China, where located a decommissioned anuclear facility. Through field investigation in the environment, the candidate reference pants are selected, the geometric characteristics of the plants are measured, the radioactivity of ${ }^{90} \mathrm{Sr},{ }^{137} \mathrm{Cs}$ and $\mathrm{Pu}$ are analyzed, and the transfer factors for the plants $(\mathrm{Bv})$ are calculated.

\section{Materials and methods}

In order to select reference plant, in a area of Sichuan province, the southwest of China, plant quadrat investigations are conducted, 5 different plant species are selected as candidate reference plants. The transfer of ${ }^{90} \mathrm{Sr}$, ${ }^{137} \mathrm{Cs}$, and $\mathrm{Pu}$ from soil to plant (organs) is studied in field.

\section{Selection of reference plants}

The vegetation of the area is flourishing. Plant quadrat investigations are conducted to select reference plant in the area. There are 3 forest land quadrats, 2 shrub land quadrats and 1 grass land quardrat made in the area. Through plant quadrat investigation, dominant species are identified. For forest land, the dominant species are Melia toosendan, Firmiana simplex,

*Corresponding Author, Tel No: +86-351-2203517; Fax No: +86-351-7020407; E-mail: lijg07@msn.com
Quercus variabilis Bl. and Nerium indicum Mill. For shrub land, the dominant species are Cotoneaster horizontalis Decne, Compositae Asteraceae, Vitexnegundo L. Var. cannabifolia and Rosales. For grass land, the dominant species are Plantago asiatica L., Artemisia annua L., Filipendula palmata (Pall.) Maxim. and Leontopodium.

Considering public understanding and environmental monitoring data available for the plants, a phoenix tree (Firmiana simplex) and a cryptomeria (Cryptomeria fourtunei) are selected for candidate reference plants of tree, a rosebay (Nerium indicum Mill) and a chaste tree (Vitex negundo Linn) as candidate reference plants of shrub, and a moxa (Artemisia umbrosa) as candidate reference plant of herb respectively. The plant and soils in root depth are sampled. The geometric characteristics of plants are measured. To obtain statistic transfer data, each plant species and paired soils are gathered in 5 different sampling points.

\section{Sampling procedure and preparation of analytical methods}

The samples are taken in the environment around a nuclear facility which was decommissioned some years ago. The radionuclides are from former release of the facility in the 1970 s.

The plant and soil samples are collected simultaneously. Soil samples are randomly taken from root depth.

For ${ }^{90} \mathrm{Sr}$ and $\mathrm{Pu}$ analysis, plant samples are dried at $105^{\circ} \mathrm{C}$, carbonized by electric stove, and passed ashing in muffle at $450^{\circ} \mathrm{C}$, then the ash is ready for analysis. The soil samples are dried at $100^{\circ} \mathrm{C}$, grind into powder and then pass through $2 \mathrm{~mm}$ sieve, ready for analysis.

For ${ }^{137} \mathrm{Cs}$ analysis, plant samples are dried by oven at $105^{\circ} \mathrm{C}$, and then grind into powder for analysis. Soil samples are air-dried naturally for 7 days and then pass through $2 \mathrm{~mm}$ sieve.

${ }^{137} \mathrm{Cs}$ is measured by S-95 r Spectrometry (made in USA by CANBERRA Company). The relative measuring efficiency of the spectrometry is $35 \%$. The detection limit for both plant and soil samples are $0.01 \mathrm{~Bq} / \mathrm{kg}$ dry weight.

${ }^{90} \mathrm{Sr}$ is measured by radio-chemical analysis followed by oxalate precipitation, HDEHP chromatograph and $\beta$ count 
for plant samples(with detection limit $0.04 \mathrm{~Bq} / \mathrm{kg}$ dry plant), and Leaching with $\mathrm{HCl}(6.0 \mathrm{~mol} / \mathrm{L})$, cation exchange, $\beta$ count for soil samples (with detection limit $0.01 \mathrm{Bg} / \mathrm{kg}$ dry soil).

$\mathrm{Pu}$ is measured by Extraction chromatography, $\beta$ count for plant samples and Leaching with chlorazotic acid, cation exchange, and $\beta$ count for soil samples. The detection limit is $0.015 \mathrm{~Bq} / \mathrm{kg}$ dry weight.

For each $\mathrm{Bv}$ data, 5 replica plant and soil samples are collected.

The research was conducted in a area in the suburbs of Guangyuan city, Sichuan Province, where located a decommissioned nuclear facility. The climate is sub-tropical and humid. The local soil is purplish soil. The physical and chemical parameters of the soil in the area are determined. Following parameters are considered: $\mathrm{pH}$ (in water), organic carbon content $(\%)$, exchangeable $\mathrm{K}$ in soil $(\mathrm{cmol}(+) / \mathrm{kg})$, exchangeable $\mathrm{Ca}$ in soil $(\operatorname{cmol}(+) / \mathrm{kg}), \mathrm{CEC}$ and etc.

The physical and chemical parameters of soil are listed in Table 1.

Table 1 The physical and chemical parameters of soil

\begin{tabular}{ll}
\hline Soil properties & Values \\
\hline $\mathrm{pH}($ in water) & 7.4 \\
$\mathrm{CEC}(\mathrm{cmol} / \mathrm{kg}$ soil $)$ & 16.4 \\
$\mathrm{E}\left(\mathrm{K}^{+}\right) \quad(\mathrm{cmol} / \mathrm{kg} \mathrm{soil})$ & 0.47 \\
$\mathrm{E}\left(\mathrm{Ca}{ }^{++}\right)(\mathrm{cmol} / \mathrm{kg}$ soil $)$ & 5.95 \\
Org. Carbon $(\%)$ & 4.3 \\
Density of soil $\left(\mathrm{kg}\right.$ dry weght $\left./ \mathrm{m}^{3}\right)$ & 1650 \\
Effective aerial density $\left(\mathrm{kg}\right.$ dry weight $\left./ \mathrm{m}^{2}\right)$ & 168 \\
\hline
\end{tabular}

\section{Geometric characteristics of the plants}

Geometric characteristics of plants are necessary for establishment of dose assessment models. Tree truck can be simplified as a cylinder. For trees, the height, diameter at chest height (the diameter measured at 1.2m's high of the tree) and the tree crown area (length $\times$ width) are measured. Tree leaf and branch samples are collected separately.

For shrubs, the height, diameter at chest height, and crown area (length $\times$ width) are measured. The leaf and branch of plants are collected as samples separately.

For herb, the height of grass is measured, and aerial parts of the plant are gathered as samples.

The geometric parameters of trees and shrubs are listed in Table 2.

The diameter and the crown area of Firmiana simplex are much higher than that of Cryptomeria fourtunei. But the height of the 2 trees is quite similar. For shrubs, the diameter and the height of Nerium indicum Mill are higher that of Vitex negundo Linn. The crown area of Vitex negundo Linn is relatively large, for this plant generally grows in large population.

The herb collected is Artemisia umbrosa. The average height is $0.76 \mathrm{~m}$, which is randomly measured from 10 plants, and the vegetation mass per unit area is about $0.05 \mathrm{~kg} / \mathrm{m}^{2}$. The herb is typical in local area, for obtaining enough mass for sample (some $8 \mathrm{~kg}$ of fresh weight is needed for radioactivity analysis), each sample needs about $160 \mathrm{~m}^{2}$ grass land area.

Table 2 Geometric characteristics of trees and shrubs

\begin{tabular}{llll}
\hline Plant & $\begin{array}{l}\text { Diameter* } \\
(\mathrm{m})\end{array}$ & $\begin{array}{l}\text { Height } \\
(\mathrm{m})\end{array}$ & $\begin{array}{l}\text { Crown area } \\
\left(\text { length } \times \text { width, } \mathrm{m}^{2}\right)\end{array}$ \\
\hline $\begin{array}{l}\text { Firmiana } \\
\text { simplex }\end{array}$ & 1.05 & 10.2 & $6.9 \times 6.2$ \\
$\begin{array}{l}\text { Cryptomeria } \\
\text { fourtunei }\end{array}$ & 0.64 & 9.8 & $3.1 \times 3.2$ \\
$\begin{array}{l}\text { Nerium } \\
\text { indicum Mill }\end{array}$ & 0.11 & 4.2 & $3.3 \times 3.7$ \\
$\begin{array}{l}\text { Vitex negundo } \\
\text { Linn }\end{array}$ & 0.07 & 2.5 & $11.4 \times 2.4$ \\
\hline
\end{tabular}

Note: “*” Diameter at chest height of $1,2 \mathrm{~m}$.

\section{Soil to plant transfer factors of reference plants}

Ash to fresh weight conversion factors of the plants are important information for the application of transfer factors, and related data of plant samples (organs) are showed in Table 3.

Table 3 Ash-to-fresh weight conversion factors for plant samples

\begin{tabular}{llll} 
& \multicolumn{2}{c}{ Unit: g ash weight/g fresh weight } \\
\hline Plant & Sampling parts & N & $\begin{array}{l}\text { Ash-to-fresh weight } \\
\text { conversion factors }\end{array}$ \\
\hline \multirow{2}{*}{ Firmiana simplex } & Leaves & 5 & $3.27 \mathrm{E}-02 \pm 2.54 \mathrm{E}-03$ \\
& Branches & 5 & $1.33 \mathrm{E}-02 \pm 1.47 \mathrm{E}-03$ \\
Cryptomeria fourtunei & Leaves & 5 & $3.84 \mathrm{E}-02 \pm 5.67 \mathrm{E}-03$ \\
& Branches & 5 & $1.67 \mathrm{E}-02 \pm 3.10 \mathrm{E}-03$ \\
Nerium indicum Mill & Leaves & 5 & $2.97 \mathrm{E}-02 \pm 1.36 \mathrm{E}-03$ \\
& Branches & 5 & $1.75 \mathrm{E}-02 \pm 1.56 \mathrm{E}-03$ \\
Vitex negundo Linn & Leaves & 5 & $3.28 \mathrm{E}-02 \pm 1.12 \mathrm{E}-03$ \\
Artemisia umbrosa & Branches & 5 & $9.90 \mathrm{E}-03 \pm 4.14 \mathrm{E}-04$ \\
& Aerial parts & 5 & $2.15 \mathrm{E}-02 \pm 1.22 \mathrm{E}-03$ \\
\hline
\end{tabular}

Note:“*” Data is given as (Average \pm Standard deviation).

The soil to plant transfer factor $(\mathrm{Bv})$ is generally defined by International Union of Radioecologists (IUR) as the concentration of radionuclide in the plant (organs), on a dry or wet weight basis, divided by that in soil in dry weight basis. The $\mathrm{Bv}$ values of ${ }^{90} \mathrm{Sr},{ }^{137} \mathrm{Cs}$, and $\mathrm{Pu}$ for the candidate reference plants are provided in Table 4 6, respectively.

For ${ }^{90} \mathrm{Sr}$ (see Table 4), the Bv of the plants are generally in the same order. The Bv of Cryptomeria fourtunei leaves and Nerium indicum Mill branches are relatively higher among the plants investigated. The $\mathrm{Bv}$ of Vitex negundo Linn branches are relatively lower. It can be seen from Table 4 that for Cryptomeria fourtunei and Vitex negundo Linn, the $\mathrm{Bv}$ of leaves are higher than that of its branches for the same species, and for Firmiana simplex and Nerium indicum Mill, the $\mathrm{Bv}$ of branches are higher than that of its leaves.

For ${ }^{137} \mathrm{Cs}$ (see Table 5), the Bv values of leaves are generally higher than that of branches for the plant species investigated (except for herb which is sampled as aerial parts). This tendency is quite different from the results of ${ }^{90} \mathrm{Sr}$. It can be seen in tables 8 that Bv values of branches of Nerium indicum Mill and Vitex negundo Linn are relatively lower in comparison with other plant samples.

For $\mathrm{Pu}$ (see Table 6), the $\mathrm{Bv}$ of Nerium indicum Mill 
branches and Cryptomeria fourtunei leaves are about 1 order's higher than that of other plants. The Bv of Vitex negundo Linn leaves are relatively lower. For trees, there is tendency that $\mathrm{Bv}$ values of leaves are higher than that of branches for the same plant. But for shrubs it's various.

Table 4 Soil to plant transfer factors (Bv) of ${ }^{90} \mathrm{Sr}$ for plants Unit: $\mathrm{Bv}:(\mathrm{Bq} / \mathrm{kg}$ fresh plant $) /(\mathrm{Bq} / \mathrm{kg}$ dry soil $)$

\begin{tabular}{lll}
\hline Plant & Sampling parts & Expected Bv values* \\
\hline \multirow{2}{*}{ Firmiana simplex } & Leaves & $4.11 \mathrm{E}-01 \pm 2.91 \mathrm{E}-01$ \\
& Branches & $4.47 \mathrm{E}-01 \pm 5.57 \mathrm{E}-01$ \\
Cryptomeria fourtunei & Leaves & $9.41 \mathrm{E}-01 \pm 1.33 \mathrm{E}+0$ \\
& Branches & $4.95 \mathrm{E}-01 \pm 5.93 \mathrm{E}-01$ \\
\multirow{2}{*}{ Nerium indicum Mill } & Leaves & $4.13 \mathrm{E}-01 \pm 2.84 \mathrm{E}-01$ \\
& Branches & $7.18 \mathrm{E}-01 \pm 1.21 \mathrm{E}+0$ \\
Vitex negundo Linn & Leaves & $3.80 \mathrm{E}-01 \pm 4.82 \mathrm{E}-01$ \\
Artemisia umbrosa & Branches & $1.96 \mathrm{E}-01 \pm 2.49 \mathrm{E}-01$ \\
& Aerial parts & $4.33 \mathrm{E}-01 \pm 3.38 \mathrm{E}-01$ \\
\hline
\end{tabular}

Note:"*" Data is given as (Average \pm Standard deviation). Sample numbers are 5 for plants.

Table 5 Soil to plant transfer factors (Bv) of ${ }^{137} \mathrm{Cs}$ for plants Unit: $\mathrm{Bv}:(\mathrm{Bq} / \mathrm{kg}$ fresh plant $) /(\mathrm{Bq} / \mathrm{kg}$ dry soil $)$

\begin{tabular}{lll}
\hline Plant & Sampling parts & Expected Bv values \\
\hline \multirow{2}{*}{ Firmiana simplex } & Leaves & $7.71 \mathrm{E}-02 \pm 5.29 \mathrm{E}-02$ \\
& Branches & $1.45 \mathrm{E}-02 \pm 1.12 \mathrm{E}-02$ \\
Cryptomeria fourtunei & Leaves & $4.93 \mathrm{E}-02 \pm 3.87 \mathrm{E}-02$ \\
& Branches & $2.09 \mathrm{E}-02 \pm 9.68 \mathrm{E}-03$ \\
& Leaves & $3.45 \mathrm{E}-02 \pm 3.55 \mathrm{E}-02$ \\
Nerium indicum Mill & Branches & $6.53 \mathrm{E}-03 \pm 5.34 \mathrm{E}-03$ \\
& Leaves & $4.89 \mathrm{E}-02 \pm 7.46 \mathrm{E}-02$ \\
Vitex negundo Linn & Branches & $5.96 \mathrm{E}-03 \pm 9.95 \mathrm{E}-03$ \\
Artemisia umbrosa & Aerial parts & $1.11 \mathrm{E}-01 \pm 1.10 \mathrm{E}-01$ \\
\hline
\end{tabular}

See note of Table 4

Table 6 Soil to plant transfer factors (Bv) of Pu for plants Unit: $\mathrm{Bv}:(\mathrm{Bq} / \mathrm{kg}$ fresh plant $) /(\mathrm{Bq} / \mathrm{kg}$ dry soil $)$

\begin{tabular}{lll}
\hline Plant & Organs & Expected Bv values* \\
\hline \multirow{2}{*}{ Firmiana simplex } & Leaves & $7.25 \mathrm{E}-01 \pm 3.56 \mathrm{E}-01$ \\
& Branches & $1.50 \mathrm{E}-01 \pm 1.48 \mathrm{E}-01$ \\
Cryptomeria fourtunei & Leaves & $1.54 \mathrm{E}+0 \pm 1.55 \mathrm{E}+00$ \\
& Branches & $3.51 \mathrm{E}-01 \pm 1.61 \mathrm{E}-01$ \\
& Leaves & $2.32 \mathrm{E}-01 \pm 1.26 \mathrm{E}-01$ \\
Nerium indicum Mill & Branches & $9.87 \mathrm{E}+0 \pm 1.97 \mathrm{E}+01$ \\
& Leaves & $8.92 \mathrm{E}-01 \pm 7.41 \mathrm{E}-01$ \\
Vitex negundo Linn & Branches & $9.05 \mathrm{E}-02 \pm 7.41 \mathrm{E}-02$ \\
Artemisia umbrosa & Aerial parts & $3.32 \mathrm{E}-01 \pm 2.15 \mathrm{E}-01$ \\
\hline
\end{tabular}

See note of Table 4.

\section{Discussions and conclusion}

\section{Comparison with the data in literature}

The soil to plant transfer factors (Bv values) of ${ }^{90} \mathrm{Sr},{ }^{137} \mathrm{Cs}$ and $\mathrm{Pu}$ in the literature are mostly drawn from field investigation, green house or growth chamber experiments in European countries contaminated by Chernobyl nuclear accident $^{3)}$ (9).

For ${ }^{90} \mathrm{Sr}, \mathrm{Bv}$ values of natural plants in field conditions obtained in Sweden are in the range of 2.1E-03 22.93), which are varied a lot depending on plant species. The Bv from herbs in forest land around Chernobyl in Russia are in $0.03 \sim 0.43^{4)}$, and $\mathrm{Bv}$ of leaves are higher than that of branches for the same species. The $\mathrm{Bv}$ of Eucalyptus trees are in 3 43 in field conditions in Spain ${ }^{5)}$. The Bv of Pinus picea in Chernobyl contaminated area, French, are in $0.3 \sim 3^{6)}$, which is similar to that of Cryptomeria fourtunei (Leaves: 0.06 3.24, branches: 0.06 1.39) of this research.

For ${ }^{137} \mathrm{Cs}$, the $\mathrm{Bv}$ of wild plants in two different ecosystems from Belarus between 0.11 0.517). The Bv from pot experiments in Chernobyl contaminated field are between $0.04 \sim 0.41^{8)}$. The Bv from natural plants in coral soil from Marshall Islands (UAS) are between 10 23 ${ }^{9}$.

For $\mathrm{Pu}$, the $\mathrm{Bv}$ of Nerium indicum Mill is 0.35 , which is similar to that of pine branches (0.7) but much higher than that of Larch branches(0.005) from the Chernobyl contaminated areas in Russia ${ }^{4}$.

The $\mathrm{Bv}$ values of ${ }^{90} \mathrm{Sr}$ and ${ }^{137} \mathrm{Cs}$ from wild plants are in a wide range, one important reason is that the origination of $\mathrm{Bv}$ data are various, including different soil types, plant species, and climate conditions.

Taranenko et al considered three vegetation layers for the dose assessment of plants, including height, mass per unit area, layer density etc. ${ }^{10)}$. The height (meters) used in the model is 9 for tree, 0.9 for shrub and 0.1 for herb. In this research, the height is $9.8 \sim 10.2 \mathrm{~m}$ for tree, $2.5 \sim 4.2$ for shrub, and $0.76 \mathrm{~m}$ for herb. The height of tree is quite similar, but the height for shrub and herb are much higher than that of Taranenko $^{10)}$. It's reasonable for the geometric characteristics of plants are varied with different ecosystems.

\section{Conclusion}

The impact assessment of radioactive effluents from nuclear facilities on ecological environment is requested in environmental impact assessment, but there is not a system for assessing the impact of ionizing radiation on non-human species in China at present. The transfer behavior of radionuclide in non-human species (animals and plants) is important basis for the dose assessment of ionizing radiation. The transfer behavior of ${ }^{90} \mathrm{Sr},{ }^{137} \mathrm{Cs}$ and $\mathrm{Pu}$ in local plant species are studied in an area of southwest of China. The plant species as candidate reference plants, including 2 tree species (Firmiana simplex, Cryptomeria fourtunei), 2 shrubs (Nerium indicum Mill,Vitex negundo Linn), and one herb (Artemisia umbrosa) are investigated. The geometric characteristics are measured for establishment of dose assessment models. Expected Bv values for the plants are provided. The results provide a basis for further study on reference plants and calculation of external and internal exposure of the plants in Southwest of China.

The following points have been considered:

(1) Due to enormous variability of plant species and habitats, the selection of reference organism is necessary. At first we need a set of reference plants of representative sizes for the basis further detailed consideration of assessment of exposures, such as tree, shrub and herb.

(2) Proper geometric models are needed for selected terrestrial reference organisms, e.g., the trunk and crown are approximately considered as simple three dimensional phantoms, for example, cylinder and cone.

(3) To meet the need for impact assessment of ionizing radiation of nuclear facilities on non human species in China, a simple and fast tool can be developed at first, where the 
construction of nuclear power plants is fast.

\section{Acknowledgment}

This work is funded by National Natural Science Foundation of China (Project No.10575088).

\section{References}

1) ICRP. 2003b. A Framework for Assessing the Impact of Ionising Radiation on Non-human Species. ICRP publication 91. Ann. ICRP 33(3),(2003)

2) ICRP (2005). The concept and use of reference animals and plants for the purposes of environmental protection (draft for discussion),(2005)

3) D.E. Robertson, D.A. Cataldo, B.A. Napier, et al., "Literature Review and Assessment of Plant and Animal Transfer Factors Used in Performance Assessment Modeling," Pacific Northwest National laboratory, U.S. INEL. Idaho National Engineering Laboratory, (2003)

4) D.Lux, L.Kammerer, W.Ruhm, et al., "Cycling of Pu, Sr, Cs and other longliving radionuclides in forest ecosystems of the $30-\mathrm{km}$ zone around Chernobyl," The Science of the Total Environment 173/174(1995):375-384 (1996)

5) F. Vaca, G. Manjon, M.Garcia-Leon., "The presence of some artificial and natural radionuclides in a Eucalyptus forest in the south of Spain," Journal of Environmental Radioactivity, 56 (2001):309-325 (2001)

6) G. Barci-Funel, J. Dalmasso, V.L. Barci, et al., "Study of the transfer of radionuclides in trees at a forest site," The Science of the Total Environment 173/174 (1995):369-373 (1995)

7) V. Putyrskaya, E. Kalinkevich, N. Goncharova.,"Is preferential flow relevant for plant uptake in areas contaminated with radionuclides?" Proceedings of XXXII Annual Meeting of ESNA/jointly organized with IUR working group soil-to-plant transfer, Warsaw, Poland, September 10-14, 2002:26-31 (2002)

8) D. Butkus, M. Konstantinova., "Studies of ${ }^{137} \mathrm{Cs}$ transfer in soil-fern system," Journal of environmental engineering and landscape management. 2005, Vo. VIII, No3, 97-102 (2005)

9) W. L. Robison, C. L. Conrado, T. F. Hamilton., "A comparative study on ${ }^{137} \mathrm{Cs}$ transfer from soil to vegetation in the Marshall Islands", Lawrence Liver, UCRL-JC-128490 (1997)

10) V Taranenko, G Pröhl and J M Gómez-Ros., "Absorbed dose conversion coefficients for reference terrestrial biota for external photon and internal exposures," J. Radiol. Prot. 24 (2004) A35-A62 (2004) 